\title{
Thermo-catalytic studies on a mixture of plastic waste and biomass
}

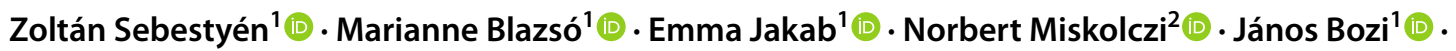 \\ Zsuzsanna Czégény ${ }^{1}[$ ]
}

Received: 2 December 2020 / Accepted: 19 June 2021 / Published online: 10 July 2021

(c) The Author(s) 2021

\begin{abstract}
The effects of various catalysts on the composition of volatile pyrolysis products of a plastic waste and biomass mixture (1:1) were studied, by pyrolyzing the mixture sample using slow and fast heating rate. Various zeolite catalysts ( $\beta$-and Y-zeolites, ZSM-5 and FCC) and nickel-molybdenum catalyst on alumina support were applied to find suitable catalysts for upgrading the quality of the thermal decomposition products of the waste mixture. A sample to catalyst ratio of 2:1 was used in the experiments. The rate of evolution of the decomposition products under slow pyrolysis was measured by thermogravimetry/ mass spectrometry (TG/MS). The composition of the pyrolyzates was analyzed in detail by pyrolysis-gas chromatography/ mass spectrometry (Py-GC/MS) method. The influence of all applied catalysts was more pronounced on the plastic content of the sample than on biomass. The pyrolysis experiments revealed that the catalysts promoted the cracking reactions of the evolved hydrocarbons; furthermore, the formation of aromatic products was enhanced remarkably in the presence of all zeolite catalysts. Beta-zeolite and ZSM-5 catalysts were found the most effective in cracking hydrocarbons to gaseous products and in aromatization, while the highest $\mathrm{CO}_{2}$ formation was obtained by FCC from the biomass part of the studied waste mixture. NiMo catalyst promoted the $\mathrm{H}_{2}$ production from the plastic part; furthermore, slight aromatization and cracking effects were also observed.
\end{abstract}

Keywords Municipal solid waste $\cdot$ Thermogravimetry/mass spectrometry $\cdot$ Catalytic pyrolysis $\cdot$ Zeolite catalysts $\cdot$ Nickelmolybdenum catalyst

\section{Introduction}

The management of municipal solid waste (MSW) is a great challenge for the human population and it requires the knowledge of the composition of the actual urban solid waste. This waste consists of various organic and inorganic components, where the two main constituents of the organic part are biomass and plastics. About $85 \%$ of MSW is biomass and plastic waste, which has high energy potential, and suitable to be utilized by thermochemical conversion. The separation of the biomass and plastic components of

Zsuzsanna Czégény

czegeny.zsuzsanna@ttk.hu

1 Institute of Materials and Environmental Chemistry, Research Centre for Natural Sciences, Magyar tudósok körútja 2, 1117 Budapest, Hungary

2 Institutional Department of MOL Hydrocarbon and Coal Processing, University of Pannonia, Egyetem utca 10, 8201 Veszprém, Hungary
MSW is an expensive process and complete separation is difficult or economically is not feasible; therefore, utilization of the multicomponent mixture is required. Co-pyrolysis and co-gasification of biomass and synthetic polymers have been published in several papers [1-7]. The organic waste materials can be converted into gas, liquid and solid products by thermochemical methods. Very important advantage of the thermal decomposition processes is the volume and mass reduction of the waste materials, which helps minimize the waste amount to be landfilled. Polyethylene (PE) and polypropylene (PP) are produced in the largest quantity among the commodity plastics. Due to their wide application as packaging materials, these two plastics make up the bulk of the plastic content of MSW. Since these polymers are rich in hydrogen atoms, they may compensate for the $\mathrm{H}$-deficient property of biomass during pyrolysis. Therefore, a more stable oil with higher yield [8] and higher heating value might be obtained by pyrolysis of MSW than from biomass [9]. Interactions between hydrocarbon polymers and lignocellulose materials are reported in several studies 
[10-12]. The main thermal decomposition step of biomass occurs at a lower temperature than that of PE and PP, and the formed char influences the degradation process of PP during slow pyrolysis [11]. The effect of the inorganic content of MSW also should be taken into consideration. During biomass pyrolysis, alkali and alkaline earth metals, especially potassium and calcium catalyze biomass decomposition and char formation. Furthermore, these inorganics are found to be the most important factors in increasing the gasification reactivity of the formed char [13, 14].

The combustible pyrolysis gas originated from MSW can be burned and converted into heat and electric current. The pyrolysis liquid of MWS is a valuable energy carrier due to its high energy content, although the biomass content of MWS releases oxygen-containing organic products, which decreases the quality of the oil. Furthermore, the pyrolysis oil contains significant amount of reactive moieties, which are keen to polymerize resulting in unstable oil [15]. Even though the composition of pyrolysis products is primarily determined by the feedstock, catalytic pyrolysis is an appropriate method to improve the energy content and the quality of the pyrolysis liquid.

The composition of the pyrolysis products can be modified by catalytic pyrolysis. Zeolites are effective catalysts for the aromatization of a wide range of feedstock including hydrocarbon plastics [16], biomass [17] or their mixture [18]. Moreover, zeolites are capable of cracking carbon-carbon bonds due to their high pore surface area, which leads to the acceleration of the thermal degradation of plastics. In fluidized bed reactors, ZSM-5 and FCC (fluid catalytic cracking) catalysts are frequently applied for catalytic conversion $[19,20]$. FCC catalyst is widely used to crack the long hydrocarbon chains into hydrocarbons of smaller molecular mass. Decreased initial degradation temperature of plastic mixture was observed in the presence of ZSM-5 catalyst [21]. Furthermore, hindering effect of cellulose and lignin was found on the catalytic activity of HZSM-5 on the fragmentation of hydrocarbon polymers under slow heating [22].

Microporous $\beta$ and $\mathrm{Y}$ types of zeolites are generally applied for breaking the carbon-carbon bonds of long chain hydrocarbons. Decreased heavy oil fraction and increased gasoline fraction was observed when MSW was pyrolyzed over Y-zeolite [23]. Beta- and Y-zeolites are often used for liquid phase esterification in the biodiesel production processes as well $[24,25]$. These types of catalysts are suitable to remove $\mathrm{CO}_{2}$ molecules from the fuel gas streams by adsorbing carbon dioxide on the surface of the zeolite [26]. Nickel-molybdenum $\left(\mathrm{NiMo} / \mathrm{Al}_{2} \mathrm{O}_{3}\right)$ catalyst is frequently applied for increasing the yield of molecular hydrogen in various reactions [27]. Kumagai et al. [28] achieved enhanced hydrogen production with a novel $\mathrm{Ni}-\mathrm{Mg}-\mathrm{Al}-\mathrm{Ca}$ catalyst system used for the thermal conversion of wood and polypropylene mixture. In the present study, $\mathrm{NiMo} /$ $\mathrm{Al}_{2} \mathrm{O}_{3}$ catalyst was applied in order to compare the effects of zeolite-based catalysts and a metal catalyst.

The influence of catalysts during pyrolysis can be studied by on-line analytical techniques (e.g., Py-GC/MS or TG/MS) or could be studied by off-line analysis of the pyrolyzate produced in a batch pyrolyzer or in a lab-scale fluidized bed reactor. Although on-line pyrolysis techniques do not provide accurate product yield data mostly due to the very small sample amount and short residence time, it is an effective approach for screening the catalytic effects, which provide supplementary information on the thermal stability of the sample and the evolution profile and product composition of the pyrolyzate. Py-GC/MS is an effective tool to investigate primary pyrolysis products, while off-line analysis can modify the composition of the reactive pyrolyzate by repolymerization [29]. In this study, the catalytic effects of four zeolite catalysts ( $\beta$ - and Y-zeolites, ZSM-5, FCC) and an alumina supported NiMo catalyst were studied on the pyrolysis of waste plastic and biomass mixture. The thermal stability and the profiles of gas evolution during slow pyrolysis were studied by thermogravimetry/mass spectrometry (TG/ MS), while the composition of pyrolysis oil was determined by pyrolysis-gas chromatography/mass spectrometry. The purpose of this work was to test and compare the efficiency of various zeolite catalysts and an alumina supported metal catalyst by focusing on the primary pyrolysis processes and products in order to provide complementary information for optimization of the utilization of waste components by catalytic pyrolysis.

\section{Experimental}

\section{Materials}

A mixture of municipal plastic waste (MPW) and agricultural waste was received from a Hungarian waste management company (Pécs). Representative pieces of waste were analyzed by FTIR to determine the composition. The following composition of the mixture was ascertained: $45.0 \%$ agricultural waste, 17.2\% LDPE and HDPE, $10.1 \%$ PP, 9.6\% PET, 6.2\% PS, 5.6\% PVC, 5.0\% waste paper, and $1.4 \%$ other. According to the result of analysis, MPW and lignocellulosic biomass were mixed in 1:1 mass ratio. The applied agricultural waste component was wheat straw. The dry sample was ground to powder $(<100 \mu \mathrm{m})$ in a Retsch MM301 mill to obtain homogenous sample for the experiments.

The catalytic effect of $\beta$-, and Y-zeolite, ZSM-5, FCC, and alumina supported nickel-molybdenum $\left(\mathrm{NiMo} / \mathrm{Al}_{2} \mathrm{O}_{3}\right)$ catalysts were tested. The most relevant characteristics of the 
Table 1 The most relevant characteristics of the catalysts

\begin{tabular}{lllll}
\hline Catalyst & Si/Al ratio & $\begin{array}{l}\text { BET } \\
\text { surface/ } \\
\mathrm{m}^{2} \mathrm{~g}^{-1}\end{array}$ & $\begin{array}{l}\text { Surface of the } \\
\text { micropores/ } \\
\mathrm{m}^{2} \mathrm{~g}^{-1}\end{array}$ & Acidity/ $\mathrm{NH}_{3} / \mathrm{g}$ \\
\hline B-zeolite & 35 & 395 & 259 & 0.48 \\
Y-zeolite & 20 & 229 & 110 & 0.38 \\
ZSM-5 & 29 & 350 & 215 & 0.44 \\
FCC & 17 & 210 & 90 & 0.30 \\
NiMo/Al $2 \mathrm{O}_{3}$ & n.a & 158 & 74 & 0.30 \\
\hline
\end{tabular}

n.a. not applicable

studied catalysts are found in Table 1 . The employed waste mixture:catalyst ratio was $2: 1$ by mass.

\section{Thermogravimetry/mass spectrometry (TG/MS)}

The thermobalance of the TG/MS system is a PerkinElmer TGS-2 instrument used with a modified furnace and a Eurotherm temperature controller. The TG is coupled to a Hiden HAL quadrupole mass spectrometer through a glass-lined metal capillary heated at $300{ }^{\circ} \mathrm{C}$. About $1.2 \mathrm{mg}$ municipal waste and $1.8 \mathrm{mg}$ mixture in the ratio of waste:catalyst $=2: 1$ were measured in an argon atmosphere at a flow rate of $140 \mathrm{~mL} \mathrm{~min}{ }^{-1}$. The samples were heated in a platinum sample pan at a rate of $10{ }^{\circ} \mathrm{C} \mathrm{min}{ }^{-1}$ from 25 to $700{ }^{\circ} \mathrm{C}$. The released volatile products were introduced through the capillary into the ion source of the mass spectrometer operated at $70 \mathrm{eV}$.

The TG curve of the pure catalysts was also measured and it was subtracted from the original TG curve of the waste and catalyst samples before data processing. Thus, the presented TG and DTG curves show the mass loss and mass loss rate exclusively of the waste sample in the case of waste and catalyst mixtures.

\section{Pyrolysis-gas chromatography/mass spectrometry (Py-GC/MS)}

Approximately $1.2 \mathrm{mg}$ waste sample or $1.8 \mathrm{mg}$ waste: catalyst $=2: 1$ mixture were pyrolyzed at $550{ }^{\circ} \mathrm{C}$ for $20 \mathrm{~s}$ in helium atmosphere using a Pyroprobe 2000 pyrolyzer interfaced to an Agilent 6890A/5973 GC/MS. The GC oven was programmed to hold at $40{ }^{\circ} \mathrm{C}$ for $4 \mathrm{~min}$ after the fast pyrolysis then to increase the temperature at a rate of $6{ }^{\circ} \mathrm{C} \mathrm{min}-1$ to $280{ }^{\circ} \mathrm{C}$ (hold for $5 \mathrm{~min}$ ). The pyrolysis products were separated on a DB-1701 capillary column ( $30 \mathrm{~m} \times 0.25 \mathrm{~mm}, 0.25 \mu \mathrm{m}$ film thickness). The mass range of $m / z, 14-500$ was measured by the mass

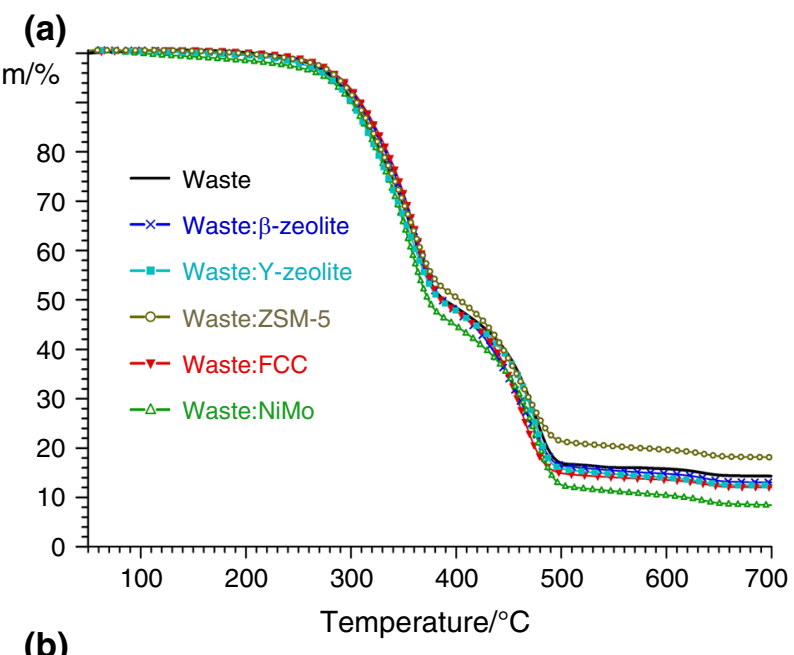

(b)

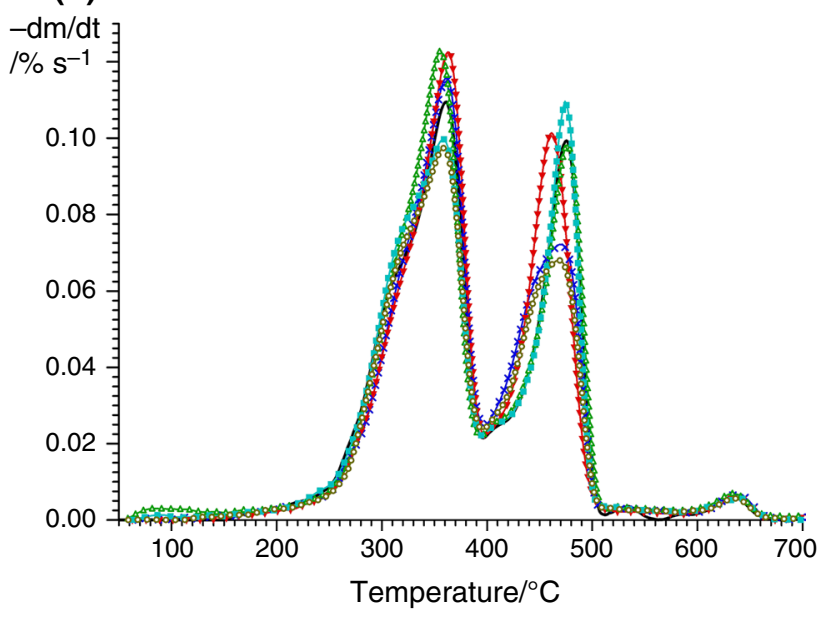

Fig. 1 a TG and b DTG curves of the waste sample with and without catalysts. The mass of catalysts was removed as described in the Experimental

spectrometer using electron impact mode at $70 \mathrm{eV}$ electron energy. Three replicate experiments were carried out on each sample.

\section{Results and discussion}

\section{Thermogravimetry/mass spectrometry (TG/MS)}

Figure 1 presents the TG and DTG curves of the waste sample as well as of the waste and catalyst mixtures. As it is seen on the TG and DTG curves, the thermal degradation of the waste sample takes place in two major steps. Biomass devolatilizes in the first stage of degradation, while the plastic component decomposes in the second stage. The main natural polymeric components of lignocellulosic biomass are cellulose, hemicellulose and lignin, while extractable organic compounds and inorganic constituents 
are also present. The release of the extractable components of biomass fraction commences at about $200{ }^{\circ} \mathrm{C}$ (Fig. 1b). The moderate shoulder on the DTG curve at around $310^{\circ} \mathrm{C}$ apparently indicates the thermal decomposition of hemicellulose, while the DTG peak at around $350{ }^{\circ} \mathrm{C}$ can be attributed to the thermal degradation of cellulose. Lignin decomposes in a wide temperature range $\left(200-600{ }^{\circ} \mathrm{C}\right)$ at a relatively slow rate [30]; therefore, the decomposition of this component of biomass does not lead to a sharp, characteristic DTG peak. The decomposition of plastics (mostly $\mathrm{PE}$ and PP) occurs in the temperature range of $390-510{ }^{\circ} \mathrm{C}$ resulting in the second decomposition stage of the waste mixture. The small, but characteristic mass loss at around $640{ }^{\circ} \mathrm{C}$ from all samples belongs to the decomposition of carbonate content of the waste sample, which was confirmed by $\mathrm{CO}_{2}$ evolution detected by TG/MS (Fig. $2 \mathrm{~h}$ ). The TG
Fig. 2 Evolution profiles of some molecular or fragment ions of gaseous products a hydrogen $-m / z, 2$, b methyl group $-m / z, 15$, c vinyl group$m / z, 27$, d ethyl and formyl groups $-m / z 29$, e methoxy group $-m / z$ 31, f propenyl group $-m / z 41, \mathbf{g}$ propyl and acetyl groups $-m / z, 43$, h carbon dioxide $-m / z, 44$

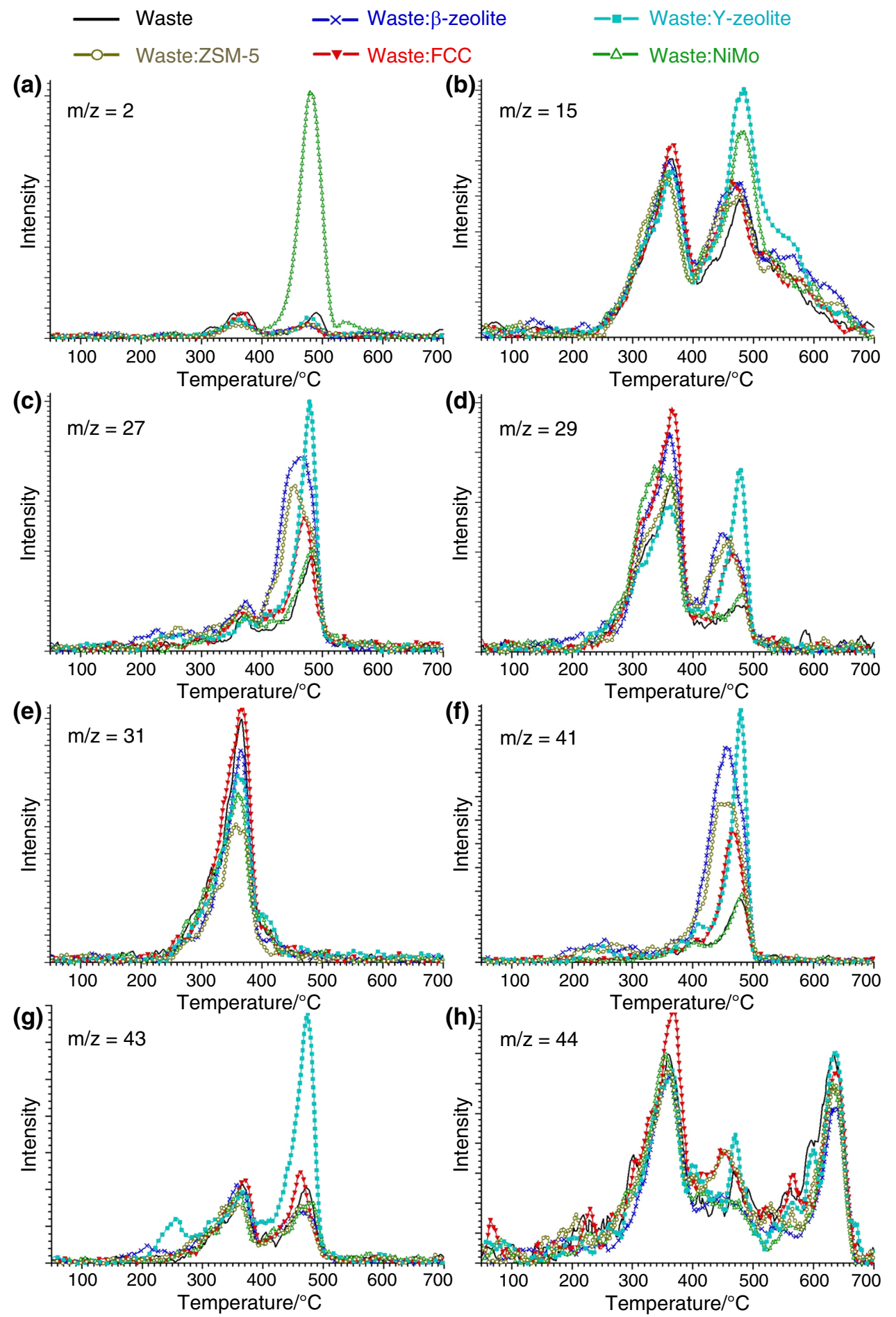


and DTG curves of the waste and waste-catalyst mixtures demonstrate that the catalysts have effect on the degree and rate of decomposition. Focusing on the thermal decomposition of the biomass component, only minor changes can be observed. The thermal decomposition starts at around the same temperature in each case. Samples containing NiMo/ $\mathrm{Al}_{2} \mathrm{O}_{3}$ and $\mathrm{FCC}$ catalysts have slightly higher maximal rate of decomposition at around $350{ }^{\circ} \mathrm{C}$ than the sample without catalyst indicating the activity of these catalysts during the decomposition of biomass fraction. The temperature of the maximal rate of decomposition does not change significantly in the presence of the catalysts studied.

The second main mass loss step can be ascribed to the thermal decomposition of the plastic content of waste. The change of DTG curves shows that the degradation of MPW component starts at somewhat lower temperature in the presence of $\beta$-zeolite, FCC, and ZSM- 5 catalysts. Moreover, in the case of FCC catalyst, the maximal rate of decomposition also shifted to a $10{ }^{\circ} \mathrm{C}$ lower temperature. The DTG peak is lower, but wider in the presence of $\beta$-zeolite and of ZSM-5, and slightly higher applying Y-zeolite catalyst. All these variations indicate catalytic interactions between the sample and the applied catalyst. The residual mass at $700{ }^{\circ} \mathrm{C}$ (TG curves, Fig. 1a) shows the amount of the carbonaceous residue. The highest amount of char was formed from the sample mixed with ZSM-5 catalyst. In the case of three other catalysts studied, the char yield slightly decreased; however, $\mathrm{NiMo} / \mathrm{Al}_{2} \mathrm{O}_{3}$, reduced the amount of char by $5 \%$. The reduced char yield can be explained by the slightly increased gas and/or pyrolysis oil formation, which is promoted by the high pore surface area of the catalysts used. This observation is in accordance with earlier studies, where slightly decreased char yield was obtained during catalytic pyrolysis of MSW performed in a batch reactor in the presence of $\beta$-zeolite, Y-zeolite, FCC and NiMo catalysts [31, 32].

Figure 2 shows the TG/MS intensity curves of some selected molecular and fragment ions of the sample with and without catalysts. Figure 3 presents the integrated intensities of typical MS ions of some volatile decomposition products. The intensity curves of the selected ions were integrated in the temperature range of $230-520{ }^{\circ} \mathrm{C}$. Hydrogen is presented by the intensity curve of the $\mathrm{m} / \mathrm{z} 2$ molecular ion (Fig. 2a). According to the shape of the $\mathrm{m} / \mathrm{z} 2$ ion curves, similar amounts of hydrogen were released during the thermal decomposition of both the biomass $\left(300-400{ }^{\circ} \mathrm{C}\right)$ and the plastic fractions $\left(420-520{ }^{\circ} \mathrm{C}\right)$ of the sample without catalyst and with zeolites (Fig. 3a). However, in the presence of $\mathrm{NiMo} / \mathrm{Al}_{2} \mathrm{O}_{3}$ catalyst, the intensity of molecular hydrogen is five times higher than without catalyst indicating strong dehydrogenation reactions under catalytic decomposition of the plastic part.

The relative amounts of hydrogen, methane, water and carbon dioxide have been estimated by integration of the intensities of their fragment or molecular ions at $m / z 2,15$, 18, and 44, respectively (Fig. 3a). The intensity of methane slightly increased in the presence of catalysts. As the ion curves indicate (Fig. 2b), methane formation is promoted by Y-zeolite and NiMo catalysts from the plastic fraction of the sample. The intensity of $\mathrm{CO}_{2}$ is slightly enhanced by FCC catalyst, whereas no significant change was found in the case of other catalysts. Figure $2 \mathrm{~h}$ illustrates that FCC catalyst promotes $\mathrm{CO}_{2}$ formation at lower $\left(250-400{ }^{\circ} \mathrm{C}\right)$ and higher $\left(400-480^{\circ} \mathrm{C}\right)$ temperature ranges demonstrating the catalytic effect on both the biomass and the plastic fractions. The peak on each $\mathrm{CO}_{2}$ curve at about $620{ }^{\circ} \mathrm{C}$ indicates the decomposition of the calcium carbonate content of waste sample. Water is the most abundant volatile product; therefore, its intensity values were divided by 5 in order to make its presentation easier in Fig. 3a. As the bar diagram illustrates, the water evolution was not much influenced by the catalysts.

The relative amounts of the $m / z 29$ (ethyl and formyl), $\mathrm{m} / z 43$ (propyl and acetyl), and $m / z 57$ (butyl) fragment ions are shown in Fig. 3b during catalytic pyrolysis in comparison with the uncatalyzed decomposition of the waste. The intensity of $\mathrm{m} / \mathrm{z}, 29$ and $\mathrm{m} / \mathrm{z}, 57$ fragments was increased in the presence of each catalyst to a different extent, while the formation of $\mathrm{m} / \mathrm{z} 43$ fragment was promoted significantly only by Y-zeolite. The fragment ions of $m / z, 29,43$, and 57 originate from various aliphatic compounds formed during the thermal decomposition of the plastic part of the waste sample (from 420 to $520{ }^{\circ} \mathrm{C}$ ). However, $\mathrm{m} / z, 29$ and 43, detected between 200 and $420{ }^{\circ} \mathrm{C}$, can be mainly attributed to $\mathrm{CHO}^{+}$and $\mathrm{CH}_{3} \mathrm{CO}^{+}$, which are the mass spectrometric fragment ions of formaldehyde, acetic acid and other oxocompounds deriving from carbohydrate and lignin components of biomass fraction of the sample. As the shape of the ion intensity curves indicates in Fig. 2d, FCC and $\beta$-zeolite promote the formation of aldehydes (illustrated by $\mathrm{CHO}^{+}$ion) during biomass decomposition, while all zeolitetype catalysts enhance the formation of $\mathrm{C}_{2} \mathrm{H}_{5}{ }^{+}$fragment of hydrocarbons during plastic decomposition at a different degree. In the presence of $\beta$-zeolite and ZSM- 5 catalysts, the ion intensity curve of $\mathrm{C}_{2} \mathrm{H}_{5}{ }^{+}$starts to increase at about $20{ }^{\circ} \mathrm{C}$ lower temperature, while the application of Y-zeolite increases the evolution rate significantly. The effect of the $\mathrm{NiMo} / \mathrm{Al}_{2} \mathrm{O}_{3}$ catalyst is negligible on the intensity of $\mathrm{C}_{2} \mathrm{H}_{5}{ }^{+}$ ions. The evolution range of $\mathrm{C}_{3} \mathrm{H}_{7}{ }^{+}$(Fig. $2 \mathrm{~g}$ ) originating from the plastic decomposition starts at about $400{ }^{\circ} \mathrm{C}$. In the presence of Y-zeolite, the intensity of propyl fragment strongly increases during the decomposition of the plastic part of the sample indicating its strong catalytic effect, while the other catalysts have no significant impact on the amount of propyl groups. The fragment ion at $m / z, 43$ can be attributed also to acetyl group in the temperature range of biomass decomposition $\left(200-400{ }^{\circ} \mathrm{C}\right)$, which is formed from various 
Fig. 3 Integrated intensities of selected molecular and fragment ions formed during TG/ MS analysis from the waste with and without catalysts: a main decomposition products, $\mathbf{b}$ alkyl fragments (and oxo-compounds), and $\mathbf{c}$ alkenyl fragment ions
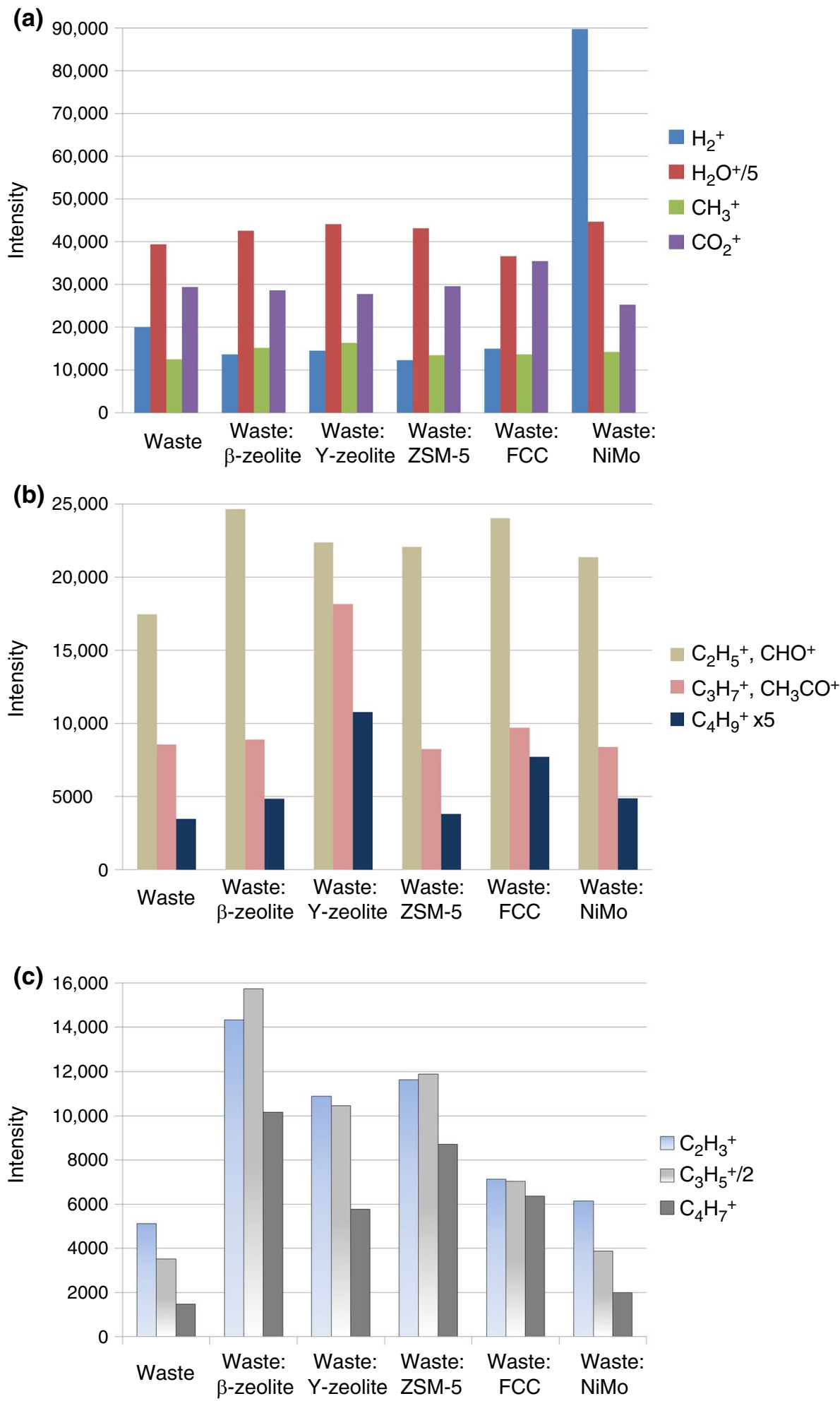

pyrolysis products of carbohydrates (e.g., acetic acid, oxocompounds). The intensity of these compounds is not influenced substantially by the presence of catalysts. Methoxy fragment ion at $m / z 31$ has also biomass origin; its main sources are methanol and hydroxyacetaldehyde. As Fig. 2e illustrates, the catalysts, with the exception of FCC, reduce moderately the amount of decomposition products, which are sources of $m / z 31$ fragment ions.

Figure $3 \mathrm{c}$ presents the area of the intensity curves of alkenyl fragment ions ( $m / z$ 27-vinyl, $m / z 41$ - propenyl, and $m / z$ 
55-butenyl groups), which are derived from unsaturated hydrocarbons. As the bar diagram demonstrates, catalysts have more significant effect on the yields of alkenyl fragments than that of the alkyl fragments. The applied zeolitetype catalysts proved to be effective in promoting the formation of small unsaturated hydrocarbon molecules from the plastic part of the sample, while the impact of NiMo catalyst on that is almost negligible. Applying $\beta$-zeolite, the intensity of the $\mathrm{C}_{2} \mathrm{H}_{3}^{+}$fragments is tripled, the amount of the $\mathrm{C}_{3} \mathrm{H}_{5}^{+}$ groups is quadrupled and the intensity of the forming $\mathrm{C}_{4} \mathrm{H}_{7}^{+}$ groups becomes eight times higher compared to the sample without catalyst. $\mathrm{C}_{2} \mathrm{H}_{3}^{+}$is the main fragment ion of ethylene, originating mainly from polyethylene during decomposition, but other alkenes also produce $m / z 27$ ion in the mass spectrometer. $\mathrm{C}_{3} \mathrm{H}_{5}^{+}$ion is the highest peak in the mass spectrum of propylene. During pyrolysis of polypropylene, the major product is propylene trimer; however, catalytic pyrolysis promotes the formation of propylene monomer. The TG/ MS results were supported by the Py-GC/MS experiments as will be presented below.

Overall, the catalysts have more pronounced influence on the thermal decomposition of the plastics fraction than on the biomass fraction of the waste.

\section{Pyrolysis-gas chromatography/mass spectrometry results (Py-GC/MS)}

Py-GC/MS experiments have been performed to analyze the composition of the pyrolyzates of the mixed waste sample with and without catalyst and identify the differences in the pyrolysis product distribution in this way. According to the TG/MS experiments, the thermal degradation of the studied samples was terminated above $500{ }^{\circ} \mathrm{C}$; therefore, the pyrolysis temperature of $550{ }^{\circ} \mathrm{C}$ was employed. During the pyrolysis process, various volatile compounds are released from both biomass and plastic parts of the sample. More than 150 decomposition products have been identified in the pyrolyzates (see Table S1 in the Supplementary material). The main pyrolysis products are unsaturated and saturated hydrocarbons originating primarily from the major plastic components (PE and PP), and oxygen-containing molecules deriving mostly from the biomass source. The total ion chromatograms (TIC) were used to calculate the area percentages of the pyrolysis products. Due to the poor resolution of the compounds eluted before $3.1 \mathrm{~min}$, the select ion chromatogram of the most intense fragment ion was used for the integration of these products. The obtained value was multiplied by a factor calculated from the ratio of selected ion intensity and total ion intensity in the mass spectrum. The identified compounds were grouped according to their chemical classes. Table 2 presents the summed area percentages of the main compound classes, while Table S1 lists the identified decomposition products of the groups.

The thermal decomposition of PE leads to a mixture of $\mathrm{n}$-alkanes, $\mathrm{n}$-alkenes and $\mathrm{n}$-alkadienes. As Table 2 indicates, the application of catalysts changes the proportion of these products in the pyrolyzate. The total amount of alkenes and alkadienes slightly decreases; however, observing the amount of each alkene and alkadiene product (Table S1), significant changes can be found in the composition of this fraction. Figures $4 a, b$ show the relative intensities of n-alkene and n-alkadiene components released during the pyrolysis of waste with and without catalysts. It can be seen that the amount of 1-butene and 1-pentene is doubled in the presence of $\beta$-zeolite and ZSM-5, and significantly increases applying other zeolite catalysts (Fig. 4a). Similarly, the relative amount of pentadiene increases among n-alkadienes in the presence of each catalyst (Fig. 4b). In this case, ZSM-5 and FCC proved to be the most effective; the relative intensity of pentadiene is almost doubled comparing to the uncatalyzed pyrolysis. Among the catalysts tested, NiMo catalyst has the least effect on the low molecular weight alkenes and alkadienes, which is the only non-zeolite-type catalyst applied in this study. On the other hand, the amount of longer chain alkene and alkadiene products decreased in the presence of all studied catalysts. The reduction is the most pronounced applying ZSM-5 or $\beta$-zeolite, and the least in the presence of NiMo. Thus, these tendencies indicate that the short alkene and alkadiene chains are formed on the expense of the

Table 2 Summed area $\%$ of the main product groups during pyrolysis of waste sample with and without catalysts

\begin{tabular}{|c|c|c|c|c|c|c|}
\hline Product & waste & waste $+\beta$-zeolite & waste + Y-zeolite & waste + ZSM-5 & waste + FCC & waste + NiMo \\
\hline$n$-Alkanes & 5.77 & 5.14 & 5.82 & 5.97 & 6.08 & 6.61 \\
\hline$n$-1-Alkenes & 28.07 & 17.96 & 25.17 & 20.23 & 26.43 & 23.11 \\
\hline Alkadienes & 9.03 & 4.49 & 6.78 & 5.16 & 7.35 & 7.75 \\
\hline PP fragments & 12.81 & 14.97 & 12.69 & 14.48 & 10.05 & 10.47 \\
\hline Aromatic hydrocarbons & 19.32 & 32.50 & 27.12 & 28.29 & 25.15 & 25.24 \\
\hline O-containing non-aromatics & 20.35 & 19.85 & 16.21 & 20.11 & 18.11 & 21.03 \\
\hline O-containing aromatics & 3.81 & 4.02 & 4.90 & 4.46 & 5.34 & 4.64 \\
\hline Others & 0.84 & 1.08 & 1.31 & 1.30 & 1.48 & 1.13 \\
\hline
\end{tabular}


Fig. 4 Peak area $\%$ of a n-alkene and $\mathbf{b} n$-alkadiene compounds as a function of the number of carbon atoms in the chain

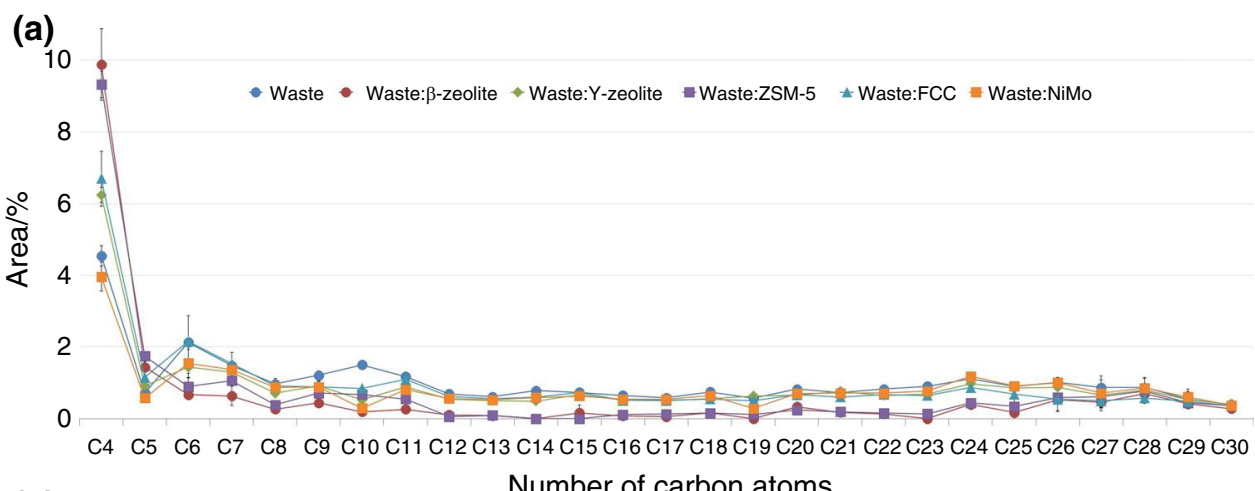

(b)

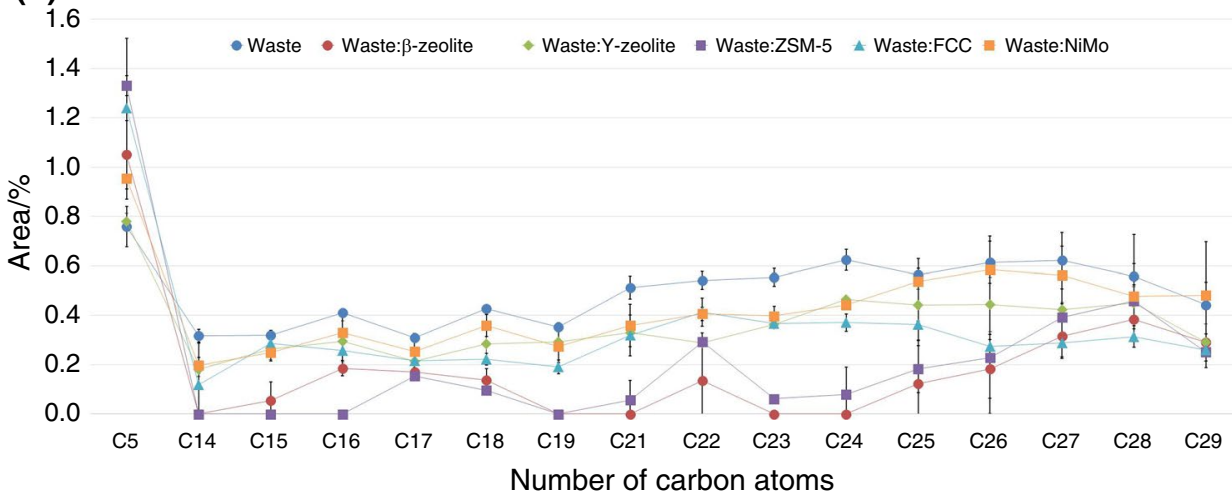

longer chains. Reduced n-alkadiene and enhanced n-alkane formation was observed during PE pyrolysis with activated carbon additive [10] indicating the hydrogenation of alkadienes. In the present study, the decrease of n-alkadienes is not accompanied by an increased n-alkane formation indicating a different mechanism. These observations indicate the strong cracking feature of the applied catalysts.

The PP-chain fragments were classified into a separate group. The main thermal decomposition product of PP is PP trimer, formed via an intramolecular radical transfer reaction [33]. The relative yield of PP trimer (2,4-dimethyl-1-heptene, see Fig. 5b), reduces significantly in the presence of zeolites and NiMo catalyst indicating the modified thermal decomposition mechanism. However, the relative amount of the PP dimer multiplied (Fig. 5a) using zeolite catalysts. Increased evolution of propene (decomposition product of both PP and PE) was observed in the presence of zeolites by both TG/MS and Py-GC/MS methods indicating the promoted formation of small alkenes during both slow and fast pyrolysis.

About one fifth (19.3\%) of the decomposition products of waste sample are aromatic hydrocarbons, and their proportion increases by $70 \%$ in the presence of $\beta$-zeolite, by 40-45\% using Y-zeolite and ZSM-5, and by 30\% applying (a)

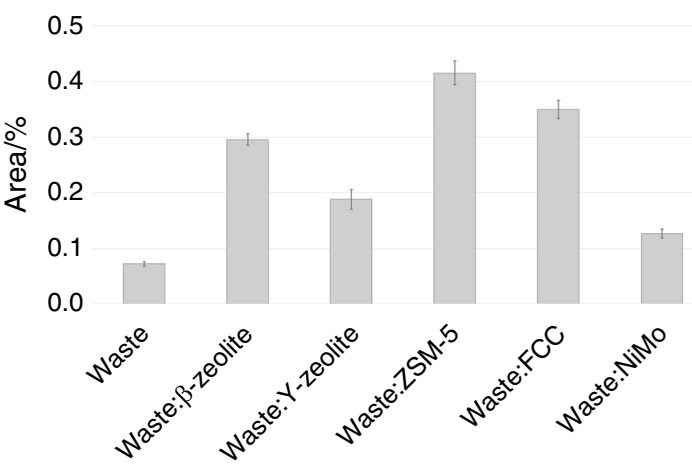

(b)

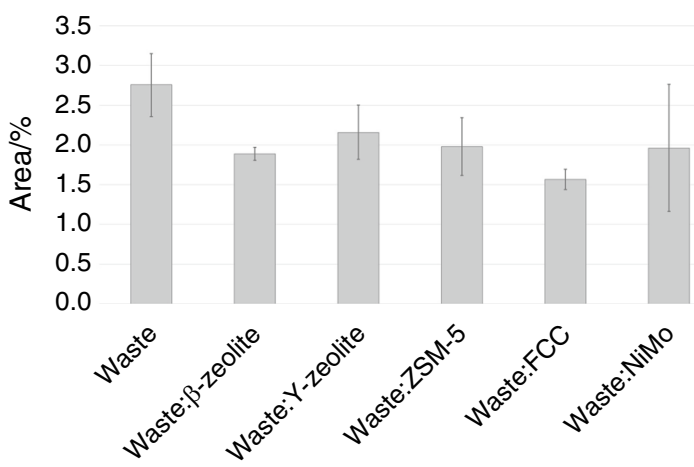

Fig. 5 GC peak area \% of selected PP decomposition products 
FCC and NiMo catalysts (Table 2). The most abundant aromatic component is styrene, which is the major decomposition product of polystyrene (PS). About one third of the aromatic hydrocarbon content of the waste pyrolyzate is styrene. The share of this component slightly decreases when zeolite catalysts are applied (Fig. 6c). At the same time, the formation of benzene, toluene, and the sum of xylene isomers (Figs. 6a, b, and d) is promoted, which are very important petrochemical materials. The area percentage of polyaromatic hydrocarbons, like naphthalene and methylnaphthalenes also significantly increases in the presence of zeolite catalysts (Table S1). The formation of aromatic hydrocarbon products was found by Dorado et al. [34] from mixtures of cellulose and plastics during catalytic fast pyrolysis using HZSM-5 zeolite catalyst. Catalytic copyrolysis of polyolefin (PE and PP) and cellulose favored the release of alkyl benzenes, while from PS-cellulose mixture, the formation of naphthalenes was more pronounced. These observations explain the changes in the composition of aromatic products in this study; the proportion of polyaromatics increases with slight decrease of the ratio of styrene. Furthermore, benzene, alkyl-benzenes, and xylenes could be formed by Diels -Alder condensation and dehydration from furan or furan derivatives and small olefin molecules during the catalytic co-pyrolysis of biomass and plastics over ZSM-5 and FCC catalysts [35, 36].

The comparison of the uncatalyzed and catalyzed decomposition of the waste sample demonstrates that the relative yield of the non-aromatic oxygen-containing compounds decreases using Y-zeolite and FCC catalysts (Table 2) indicating the impact of these catalysts on the biomass part. Cellulose depolymerizes during pyrolysis resulting in the formation of levoglucosan (1,6-anhydro- $\beta$-D-glucopyranose), which is the most abundant component of the non-aromatic oxygen-containing molecule group (See Table S1 in Supplementary material). Other anhydrosugars and smaller oxygencontaining molecules like hydroxyacetaldehyde and acetic acid are the further members of this group. Figure 7 presents the peak area $\%$ of selected oxygen-containing pyrolysis products. Acetic acid is a characteristic decomposition product of hemicellulose. The relative amount of this compound decreases by $40-60 \%$ in the presence of zeolites (see Fig. 7a); ZSM-5 and $\beta$-zeolite proved to be the most effective catalysts probably due to their strong decarboxylation feature. The disadvantageous acidity of the pyrolysis oil significantly reduces in this way. The relative amount of levoglucosan slightly decreased when Y-zeolite and FCC catalyst were applied (Fig. 7b) indicating that the depolymerization (a)

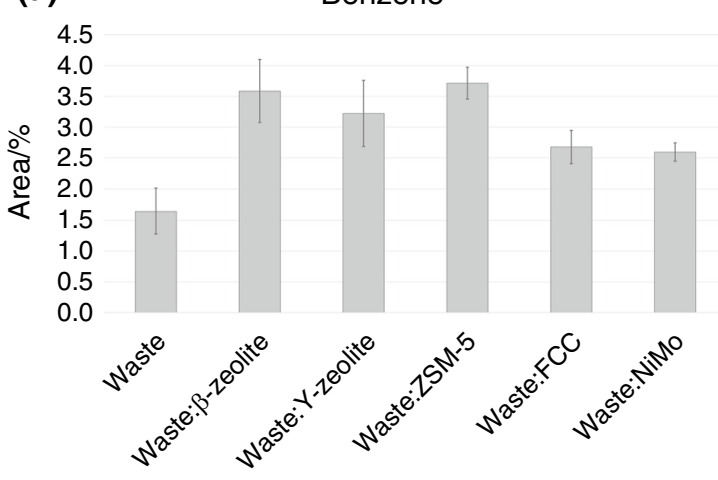

(c)

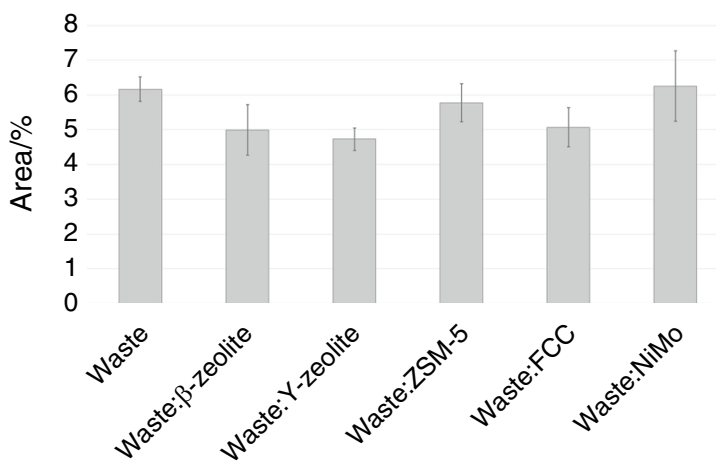

(b)

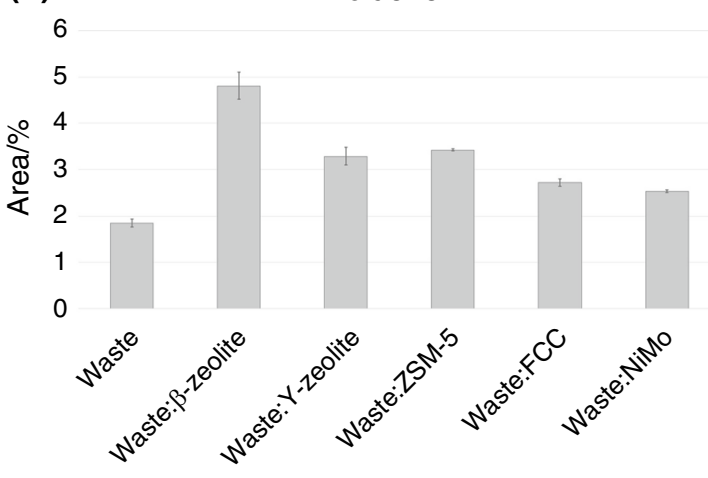

(d)

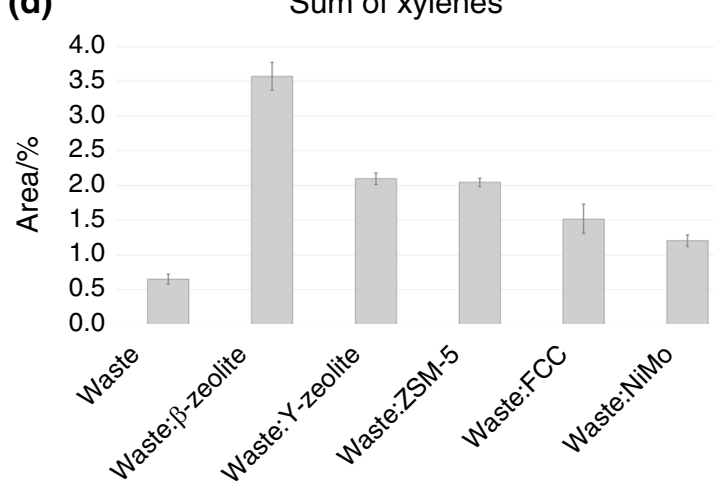

Fig. 6 GC peak area \% of selected aromatic compounds 

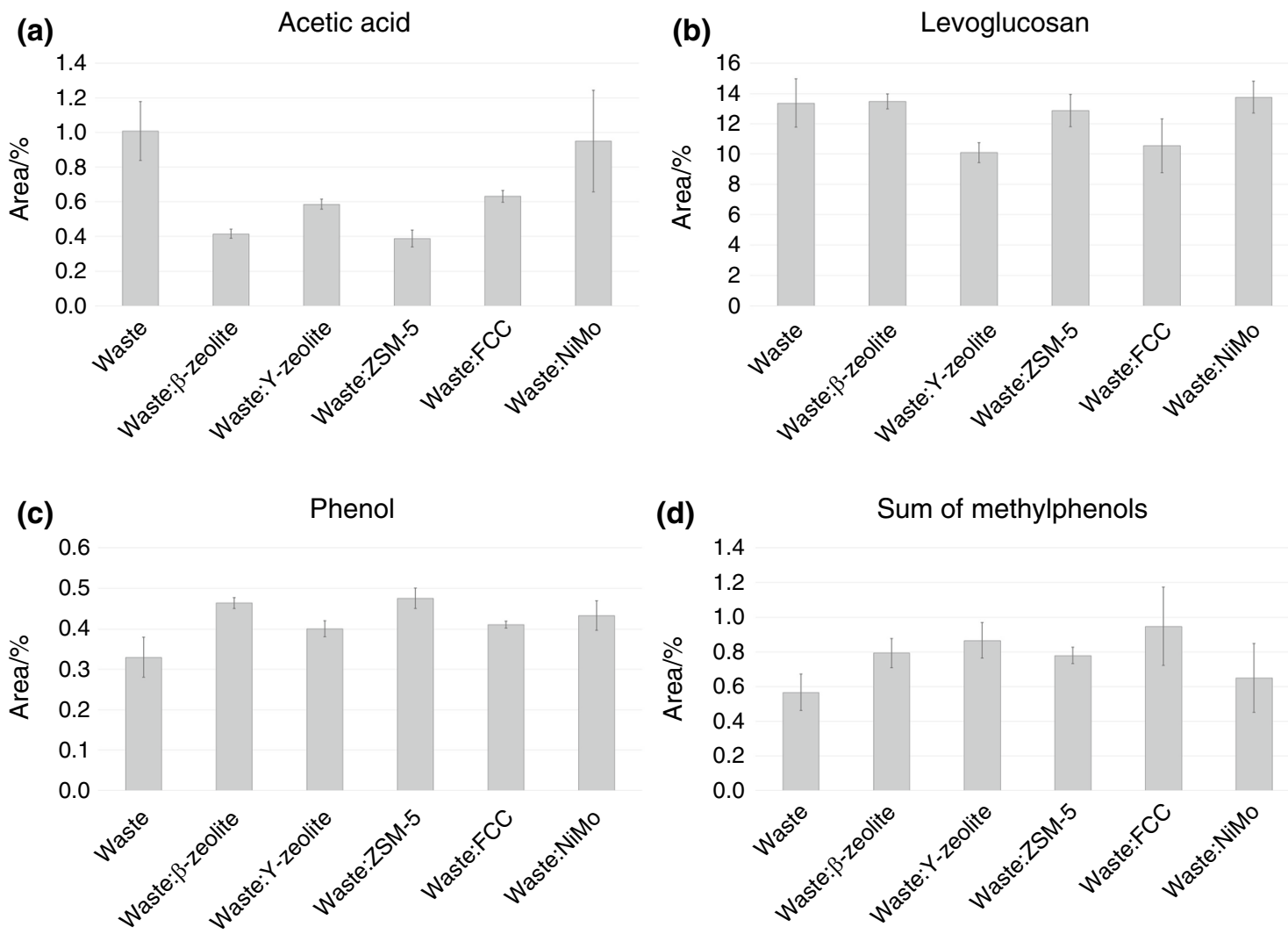

Fig. 7 GC peak area \% of selected oxygen-containing compounds

mechanism of cellulose is moderately affected by these catalysts. The amount of levoglucosan changed within the standard deviation in all other cases.

The change in the relative yield of aromatic oxygen-containing molecules includes the slightly larger yield of phenol (Fig. 7c) and the significant increase of methyl-phenol derivatives in the presence of each catalyst (Fig. 7d). It is likely that the catalysts promote the hydrogenation of lignin leading to the release of more aromatic volatile products and to the formation of less char from the lignin component.

\section{Conclusions}

The efficiency of catalysts directing the primary pyrolysis of MSW is the most important information for upgrading the energy content by catalytic pyrolysis. The purpose of this work was to test and compare the impact of various catalysts on the primary pyrolysis of MSW. The effect of various zeolite type catalysts and an alumina supported NiMo catalyst was intensities of hydrocarbons of smaller molecular mass. The detailed analysis of the alkene and alkadiene decomposition products indicated multiplied yields of C4-C5 products, and a marked studied on the thermal degradation of a MSW sample. TG/MS and Py-GC/

MS techniques were applied in order to reveal changes in the thermal stability and composition of the pyrolyzate. The TG/MS results revealed that under gradual heating the catalytic effect was more pronounced on the plastic part than on the biomass component of waste sample. The significant cracking effect of catalysts was proved by the considerably enlarged decrease in the amounts of the longer molecular chain alkenes and alkadienes. $\beta$-Zeolite and ZSM- 5 had the most remarkable cracking and aromatization effects during the thermal decomposition. The enhanced yield of propylene among the gaseous products and the reduced amount of propylene trimer also verified the modified decomposition path of PP and the cracking effect of zeolites. One of the main advantages of the zeolite catalysts on the decomposition of the biomass part was the reduction of acetic acid by $40-60 \%$ in the oil. ZSM-5 and $\beta$-zeolite was the most effective, but all zeolites improved the oil quality from this point of view. Moreover, enhanced formation of the lignin-derived phenol and methoxyphenol compounds was observed. Both the decreased acidity and the increased aromatic content improve the oil quality. The share of aromatic hydrocarbons increased by $70 \%$ in the presence of $\beta$-zeolite, by $40-45 \%$ when Y-zeolite or ZSM-5 catalysts were applied, and FCC and NiMo catalysts improved the ratio of the aromatic products by $30 \%$. 
In short, each tested zeolite catalyst upgraded the quality of the oil to a different extent by decreasing the acidity and increasing the aromatic content of the oil, which enhances the octane rating of the product. Increased fragmentation reactions were also observed generally in the presence of zeolites. ZSM-5 and $\beta$-zeolite were the most effective catalysts in decreasing the acidity, and increasing the chain fragmentation and aromatics formation under the applied experimental conditions. The alumina supported NiMo catalyst was effective in $\mathrm{H}_{2}$ production from the plastic components, moreover slight aromatization and cracking effect was observed, as well.

In summary, primary pyrolysis reactions have been studied by on-line analytical techniques (Py-GC/MS and TG/ MS), which proved to be successful methods for screening the catalytic effects, and providing supplementary information on the thermal stability of the sample and the evolution profiles of the components of the pyrolyzate. The applied on-line analytical techniques are effective tools to investigate primary pyrolysis products, while off-line analysis can modify the composition of the reactive pyrolyzate by repolymerization. More than 150 decomposition products were identified and the relative intensities of these products were determined in the pyrolyzates of the waste sample with and without catalysts. The results of on-line analysis proved that testing and comparing the efficiency of various catalysts, by focusing on the primary pyrolysis processes and products, could be applied as a novel way for optimization of the utilization of waste components by catalytic pyrolysis.

Supplementary Information The online version contains supplementary material available at https://doi.org/10.1007/s10973-021-10962-5.

Acknowledgements The authors are grateful to the NKFIH (Hungary) for financing the TNN 123499 and OTKA PD 132438 projects. The research was supported by the European Union and the State of Hungary, co-financed by the European Regional Development Fund within the project VEKOP-2.3.2-16-2017-00013.

Author contributions ZS: investigation, data analysis, writing-original draft. MB writing — review and editing. EJ: writing—review and editing. NM: conceptualization, sample preparation. JB: data analysis. $\mathrm{ZC}$ : conceptualization, writing-original draft.

Funding Open access funding provided by ELKH Research Centre for Natural Sciences.

Open Access This article is licensed under a Creative Commons Attribution 4.0 International License, which permits use, sharing, adaptation, distribution and reproduction in any medium or format, as long as you give appropriate credit to the original author(s) and the source, provide a link to the Creative Commons licence, and indicate if changes were made. The images or other third party material in this article are included in the article's Creative Commons licence, unless indicated otherwise in a credit line to the material. If material is not included in the article's Creative Commons licence and your intended use is not permitted by statutory regulation or exceeds the permitted use, you will need to obtain permission directly from the copyright holder. To view a copy of this licence, visit http://creativecommons.org/licenses/by/4.0/.

\section{References}

1. Sajdak M, Slowik K. Use of plastic waste as a fuel in the co-pyrolysis of biomass: Part I. The effect of the addition of plastic waste on the process and products. J Anal Appl Pyrol. 2014;107:267-75.

2. Xue Y, Zhou S, Brown RC, Kelkar A, Bai X. Fast pyrolysis of biomass and waste plastic in a fluidized bed reactor. Fuel. 2015;156:40-6.

3. Pinto F, Franco C, André RN, Miranda M, Gulyurtlu I, Cabrita I. Co-gasification study of biomass mixed with plastic wastes. Fuel. 2002;81:291-7.

4. Soler A, Conesa JA, Iñiguez ME, Ortuño N. Pollutant formation in the pyrolysis and combustion of materials combining biomass and e-waste. Sci Tot Environ. 2018;622-623:1258-64.

5. Luo J, Li Q, Meng A, Long Y, Zhang Y. Combustion characteristics of typical model components in solid waste on a macroTGA. J Therm Anal Cal. 2018;132(1):553-62.

6. Conesa JA, Soler A. Decomposition kinetics of materials combining biomass and electronic waste. J Therm Anal Cal. 2017;128(1):225-33

7. Rathnayake D, Ehidiamhen PO, Egene CE, Stevens CV, Meers $\mathrm{E}$, Mašek $\mathrm{O}$, Ronsse F. Investigation of biomass and agricultural plastic co-pyrolysis: Effect on biochar yield and properties. J Anal Appl Pyrol. 2021;155:105029.

8. Kumagai S, Yamamoto M, Takahashi Y, Kameda T, Saito Y, Yoshioka T. Impact of common plastics on cellulose pyrolysis. Energy Fuels. 2019;33(7):6837-41.

9. $\mathrm{Hu} \mathrm{Y}$, Wang $\mathrm{H}$, Lakshmikandan $\mathrm{M}$, Wang S, Wang Q, He Z, Abomohra AE. Catalytic co-pyrolysis of seaweeds and cellulose using mixed ZSM-5 and MCM-41 for enhanced crude bio-oil production. J Therm Anal Cal. 2021;143:827-42.

10. Jakab E, Blazsó M, Faix O. Thermal decomposition of mixtures of vinyl polymers and lignocellulosic materials. J Anal Appl Pyrol. 2001;58-59:49-62.

11. Jakab E, Várhegyi G, Faix O. Termal decomposition of polypropylene in the presence of wood-derived materials. J Anal Appl Pyrol. 2000;56:273-85.

12. Kumagai S, Fujita K, Takahashi Y, Nakai Y, Kameda T, Saito $\mathrm{Y}$, Yoshioka T. Beech wood pyrolysis in polyethylene melt as a means of enhancing levoglucosan and methoxyphenol production. Sci Rep. 2019;9:1955.

13. Aluri S, Syed A, Flick DW, Muzzy JD, Sievers C, Agrawal PK. Pyrolysis and gasification studies of model refuse derived fuel (RDF) using thermogravimetric analysis. Fuel Proc Technol. 2018;179:154-66.

14. Li Y, Xing X, Ma P, Zhang X, Wu Y, Huang L. Effect of alkali and alkaline earth metals on co-pyrolysis characteristics of municipal solid waste and biomass briquettes. J Therm Anal Cal. 2020;139(1):489-98.

15. Letho J, Oasma A, Solantausta Y, Kytö M, Chiaramonti D. Review of fuel oil quality and combustion of fast pyrolysis bio-oils from lignocellulosic biomass. Appl Energy. 2014;116:178-90.

16. Sinfrônio FSM, Souza AG, Santos IMG, Fernandes VJ, Novák CS, Éhen ZS. Influence of H-ZSM-5, Al-MCM-41 and acid hybrid ZSM-5/MCM-41 on polyethylene decomposition. J Therm Anal Cal. 2006;85(2):391-9. 
17. Aho A, Kumar N, Eranen K, Salmi T, Hupa M, Yu DM. Catalytic pyrolysis of woody biomass in a fluidized bed reactor: influence of the zeolite structure. Fuel. 2008;87:2493-501.

18. Zhao Y, Yang X, Fu Z, Li R, Wu Y. Synergistic effect of catalytic co-pyrolysis of cellulose and polyethylene over HZSM-5. J Therm Anal Cal. 2020;140:363-71.

19. Zhang X, Lei H, Zhu L, Qian M, Zhu X, Wu J, Chen S. Enhancement of jet fuel range alkanes from co feeding of lignocellulosic biomass with plastic via tandem catalytic conversions. Appl Energy. 2016;173:418-30.

20. Zhang Y, Yu D, Li W, Gao S, Xu G, Zhou H, Chen J. Fundamental study of cracking gasification process for comprehensive utilization of vacuum residue. Appl Energy. 2013;112:1318-25.

21. Paula TP, Marques MFV, da Costa Marques MR. Infuence of mesoporous structure ZSM-5 zeolite on the degradation of Urban plastics waste. J Therm Anal Cal. 2019;138(5):3689-99.

22. Sebestyén Z, Barta-Rajnai E, Bozi J, Blazsó M, Jakab E, Miskolczi N, Sója J, Czégény Z. Thermo-catalytic pyrolysis of biomass and plastic mixtures using HZSM-5. Appl Energy. 2017;207:114-22.

23. Syamsiro M, Saptoadi H, Norsujianto T, Noviasri CS, Alimuddin Z, Yoshikawa K. Fuel oil production from municipal plastic wastes in sequential pyrolysis and catalytic reforming reactors. Energy Proc. 2014;47:180-8.

24. Yue Y, Liu H, Zhou Y, Bai Z, Bao X. Pure-phase zeolite beta synthesized from natural aluminosilicate minerals and its catalytic application for esterification. Appl Clay Sci. 2016;126:1-6.

25. Doyle AM, Albayati TM, Abbas AS, Alismaeel ZT. Biodiesel production by esterification of oleic acid over zeolite Y prepared from kaoline. Renew Energy. 2016;97:19-23.

26. Losch J. Adsorption of $\mathrm{CO}_{2}$ on zeolites at moderate temperatures. Energy Fuel. 2005;19:1153-9.

27. Jinlong L, Tongxiang L, Chen W. Investigation of hydrogen evolution activity for the nickel, nickel-molybdenum nickel-graphite composite and nickel reduced graphene oxide composite coatings. Appl Surf Sci. 2016;366:353-8.

28. Kumagai S, Alvarez J, Blanco PH, Wu C, Yoshioka T, Olazar $\mathrm{M}$, Williams PT. Novel $\mathrm{Ni}-\mathrm{Mg}-\mathrm{Al}-\mathrm{Ca}$ catalyst for enhanced hydrogen production for the pyrolysis-gasification of a biomass/ plastic mixture. J Anal Appl Pyrol. 2015;113:15-21.

29. Kumagai S, Takahashi Y, Kameda T, Saito Y, Yoshioka T. Quantification of cellulose pyrolyzates via a tube reactor and a pyrolyzergas chromatograph/flame ionization detector-based system. ACS Omega. 2021;6:12022-6.

30. Jakab E. Analytical techniques as a tool to understand the reaction mechanism. In: Pandey A, Bhaskar T, Stocker M, Sukumaran RK, editors. Recent advances in thermo-chemical conversion of biomass. Boston: Elsevier; 2015. p. 75-108.

31. Miskolczi N, Ates F, Borsodi N. Comparison of real waste (MSW and MPW) pyrolysis in batch reactor over different catalysts. Part II: Contaminants, char and pyrolysis oil properties. Biores Technol. 2013;144:370-9.

32. Ates F, Miskolczi N, Borsodi N. Comparision of real waste (MSW and MPW) pyrolysis in batch reactor over different catalysts. Part I: Product yields, gas and pyrolysis oil properties. Biores Technol. 2013;133:443-54.

33. Lattimer RP. Direct analysis of polypropylene compounds by thermal desorption and pyrolysis-mass spectrometry. J Anal Appl Pyrol. 1993;26:65-92.

34. Dorado C, Mullen CA, Boateng AA. Origin of carbon in aromatic and olefin products derived from HZSM-5 catalyzed co-pyrolysis of cellulose and plastics via isotopic labeling. Appl Catal B: Env. 2015;162:338-45.

35. Cheng YT, Huber GW. Production of targeted aromatics by using Diels-Alder classes of reactions with furans and olefins over ZSM-5. Green Chem. 2012;14:3114-25.

36. Kumar KP, Srivivas S. Catalytic co-pyrolysis of biomass and plastics (polypropylene and polystyrene) using spent FCC catalyst. Energy Fuels. 2020;34(1):460-73.

Publisher's Note Springer Nature remains neutral with regard to jurisdictional claims in published maps and institutional affiliations. 